\title{
Characteristic Waterfront Landscape Space Design
}

\author{
Chen Suning
}

Suzhou Art \& Design Technology Institute

Keywords: Characteristic; Waterfront landscape; Space design

\begin{abstract}
The rapid development of economy has also driven the reform in scientific area and earth-shaking changes have taken place in various fields of the society. Many places in the country have paid attention to waterfront space design from the perspective of cultural development under the influence of the design philosophies of western countries. In order to manifest the unique characteristics of a city, the quality of waterfront space design has influenced the cultural deposits of the entire city directly. However, the waterfront space design in many cities are the same at present. They also pursue the same space design philosophy without any novel benefits. Therefore, new reflections on waterfront space design are needed in different cities, and how to improve the level of waterfront space design in different cultural regional space has become an important topic for the development of urban cultural development. Therefore, cultural characteristics of different regions need to be considered, and landscape cultural system needs to be organized during the process of waterfront regional space design, and important waterfront space design project needs to be constructed according to the main cultural characteristics in order to manifest cultural characteristics and its own charm of the region.
\end{abstract}

\section{Introduction}

Urban modernization construction has been advancing in China, which relies on the advanced science and technology methods. With the increasingly more frequent cultural and artistic communications in various countries in the world, people's aesthetic values have also been changing. Fragmentation, isolation and minicape have happened in regional characteristic cultural landscape space design of many cities in China. Urban waterfront space has improved people's life and satisfied urban residents' demands for daily activities. However, waterfront space design has not highlighted the cultural characteristics and regional landscape of contemporary cities, and people living in this area cannot reach sense of cultural identity. Therefore, new reflections need to be conducted considering waterfront regional space design of Chinese cities in order to highlight cultural deposits of the region and improve the cultural smells generally.

\section{Manifestation of Cultural Deposits of Urban Waterfront Space Design}

With the difference of regional dimensionality and longitude, the space and places in which we live are bound to change. During the process of urban regional culture creation and inheritance, it needs to be inherited and deduced by the culture of landscape space. The so-called cultural landscape is the daily space places with regional characteristics that we see in daily life, and it can be understood as the interactional result of human beings and places for thousands of years. It is also the common manifestation of modern people's values and ideologies. When people live in the same place for a long time, various colorful life would be bred in the space they live in. People would recreate and inherit the space in order to highlight cultural deposits. With the continuous advancement of urbanization, in order to manifest cultural characteristics and uniqueness of a city, waterfront is often used to manifest the charm and intelligence of the city, which manifest the charm of contemporary urban culture and urban artistic colors. Under the influence of cultural ideologies of the new era, people should understand how to explore values of contemporary regional culture, use modern cultural smells to highlight the inheritance and recreation of the whole city, highlight urban individuation and identifiability and satisfy people's real demands for urban waterfront in the 
new era.

\section{Discussion on the Overall Ideology of the Current Urban Waterfront Space Design}

\subsection{Real demands of cultural reconstruction during the process of urban waterfront space design}

An important carrier of urban space activity is waterfront region, which can present local cultural characteristics and urban flexibility sufficiently, especially concentrated reflection of urban culture and artistic charm. Then, it is accurate description of the overall ideology of urban waterfront landscape space design. Linear space is adopted in many waterfront regions in China, and many waterfronts are across the river. At present, urban waterfront space landscape has become an important area for foreign people to understand urban culture and city scape. Concerning urban waterfront space landscape design, on the one hand, it can manifest historical and cultural characteristics of the city sufficiently; on the other hand, it satisfies city residents' functional demands of daily life, and comprehensive effects are obtained during continuous development and research. During the design process of many Chinese large-scale waterfront landscape space design, novel design ideologies are severely lacked, and monotonous ideology is usually adopted to realize design of waterfront space landscape. Therefore, functional reflection of cultural nodes should be paid attention to during urban waterfront landscape design. Also, important nodes should be chosen for urban culture, and different cultural characteristics should be differentiated to realize space landscape design in order to highlight the unique cultural characteristics, style and individuality of contemporary city. Only if the reconstruction function of important nodes during urban waterfront landscape design is attached with enough importance can the overall ideology of urban waterfront landscape be designed more clearly. On the premise of satisfying people's demands for activity, the artistic charms of cultural deposits of cities can be further improved.

\subsection{Overall planning of landscape cultural system of urban waterfront landscape space design}

To a city, in order to highlight the cultural characteristics and artistic colors of the city and have more people understand the overall characteristics of the city, urban waterfront landscape space design is needed. In the overall urban waterfront landscape space design, a landscape cultural system with cultural smells should be designed in order to have an integrate grasp and understanding of the cultural mechanism of the city, and major characteristics of the local cultural mechanism should be referred to construct the environment space pattern. Regionalism is a major characteristic of local urban cultural landscape, which belongs to urban space landscape design, and it has formed cultural attribute with unique characteristics in the long time of historical evolvement. In the long time of development, the product of the combination of natural space and human culture came into being, which formed environment space pattern with unique characteristics in different regions. In the whole space system, space image of material morphologist and objective immaterial cultural image are presented in the whole space system, such as forest land, farm, architecture, rivers and so on, which are not only practical, but also are shouldered with local cultural characteristics. Therefore, the city's cultural characteristics should be adhered to during the process of urban waterfront landscape space design, and design forms which do not integrate with the city's cultural characteristics should not be pursued blindly. More focus should be attached to the diversified and complicated cultural mechanism and the transmission of regional space function, which should be reflected in the whole process of urban waterfront landscape space design.

\section{New Reflections on Contemporary Urban Waterfront Landscape Space Design}

\subsection{Design requirements on urban waterfront landscape space design should be made clear}

If a city wants to attract more people to develop in it, its unique charms and cultural deposits should be highlighted during urban construction. Therefore, modern elements and cultural elements should be integrated into the process of urban waterfront landscape space design. The department of 
urban waterfront landscape space design should pay high attention to the management of urban waterfront landscape space design, and supervision should be proper. They should have a full understanding of people's real demands of urban waterfront landscape space design and what kind of space landscape should be created to satisfy people's real demands in daily life. Therefore, during the process of urban waterfront landscape space design, the first and foremost thing is to be familiar with the whole urban waterfront landscape space design, landscape space plan and the implementation content, and the above design requirements and principles should be adhered to during the construction process. They should be clear about the specific conditions of the whole urban waterfront landscape space design, since only in this way can the new image and characteristic features of the contemporary city be highlighted. Different regions have their own cultural and historical legends. During urban waterfront landscape space design, local cultural features, stories and legends can be transformed to the cultural soul of the region. Not only local residents' aesthetic requirements and functional requirements of urban waterfront landscape space design should be satisfied, local cultural characteristics should also be fully integrated in order to highlight its flexibility during the whole landscape space construction process.

\subsection{Constructing the general objective for overall space design according to urban waterfront landscape space design}

As for urban waterfront landscape space design, only if people are familiar with the project content and specific design requirements of urban waterfront landscape space design can the most proper general objective for urban waterfront landscape space design be constructed in order to manifest the unique cultural deposits of the region to foreign people and construct comprehensive waterfront landscape region. Also, the waterfront landscape region should integrate sports, citizen entertainment, science, education and environment protection. For example, the design of Xi'an urban waterfront landscape space design should have a full understanding of local residents' usage requirements for waterfront space landscape. Meanwhile, there should be an overall planning in the whole urban waterfront landscape space design according to local people's cultural characteristics and customs, which should be modified and improved incessantly in the continuous understanding of local conditions and customs. After the work is finished, the general design objective of Xi'an waterfront space landscape can be constructed according to the specific investigation information. Meanwhile, modern urban elements and local culture should be integrated in order to highlight the cultural deposits and local customs of Xi'an.

\subsection{Planning and organizing the overall ideology of urban waterfront landscape space design purposefully}

As for waterfront landscape space design of different regions, cultural design should be conducted to the structure of the overall landscape space, and cultural characteristics should be paid attention in structural description of the whole urban waterfront landscape space design. To build a landscape space system with structural characteristics, after organization of the cultural connotation of the region, cultural elements of different individuals should be expressed in the form of combination and divisions. Meanwhile, the combination of meaning and image of the local space should be referred to optimize the whole cultural system, construct an integrate narration landscape structure. The design ideology of the space should be made clear in order to express an integrate urban waterfront landscape space design. In the process of urban waterfront landscape space design, it should be noted that presentation of the historical and cultural characteristics should be implemented properly, and the ecological functions of the waterfront region should be embodied. How to cater to people's actual demands in daily life should be thought about, and the image positioning of the whole urban waterfront landscape space design should be the most appropriate. Meanwhile, in the whole urban waterfront landscape space design, how to integrate modern elements in it should also be considered. Therefore, in the whole urban waterfront landscape space design process, the ideology of urban waterfront landscape space design should be made clear, and the integrate cultural veins should be organized in order to have a clear understanding of the real demands of urban waterfront landscape space design and form the overall ideology of the 
combination of water town, functional distribution integration and cultural manifestation.

\subsection{Applying local cultural deposits to the process of urban waterfront landscape space design sufficiently}

In the process of urban waterfront landscape space design, historical and cultural deposits of the region should be fully explored in the design of the whole waterfront space, and the unique context system of the region should be integrated, especially many cities with historical and cultural characteristics. The design of the city's waterfront space should combine cultural and historical towns of surrounding places, and combination with surrounding historical towns should be organized integrally. At the same time, cultural elements of the waterfront design should be organized well; this cultural deposit should be transformed into tourists' real feelings. The landscape image should be described, and core cultural connotations should be organized well. In the investigation process of towns with historical and cultural characteristics, some famous historical cities have water transportation culture, including water transportation construction culture, water transportation food culture, water transportation entertainment culture, water transportation spirit culture and local business culture, and this extracted water transportation cultural elements can be integrated into local waterfront design process, and the cultural deposits of the region should be implemented to the whole urban waterfront landscape space design.

\section{Conclusion}

With the continuous advancement of modernization construction process, many cities present their urban waterfront landscape space design in order to highlight the region's cultural charms and artistic characteristics. Though the urban waterfront landscape space design in many Chinese cities have improved, most of them only follow suit blindly without considering their own cultural characteristics. Therefore, the urban waterfront landscape space design cannot realize ideal application effects. Local cultural characteristics and functional demands must be abided by in the process of urban waterfront landscape space design in order to realize landmark and regional sense of identity.

\section{References}

[1] Zhu Qianmin \& Zhu Xuemei; On Building Scientific Waterfront Space Landscape Illumination Design Mode[J]; Modern Decoration(theory); 2012(03)

[2] Yan Yu \& Chen Xing; Research on Waterfront Landscape Construction[J]; Anhui Agricultural Science; 2011(13)

[3] Chen Dongtian; Research on the Construction of Urban Waterfront Landscape[J]; Shanxi Architecture; 2010(33) 